\title{
TRÊS ETAPAS PARA UMA ANTROPOLOGIA HISTÓRICA DO NEOLIBERALISMO REALMENTE EXISTENTE ${ }^{1}$
}

\author{
Loïc Wacquant
}

\begin{abstract}
A antropologia do neoliberalismo se polarizou entre um modelo econômico hegemônico, ancorado por variantes do domínio de mercado, e uma abordagem rebelde, alimentada por derivações da noção foucaultiana de governamentalidade. Ambas as noções dissimulam o que é "neo" no neoliberalismo: a reengenharia e a reestruturação do Estado como a agência principal que estabelece regras e conforma as subjetividades, relações sociais e representações coletivas apropriadas à produção de mercados. Eu desenvolvo o conceito de Bourdieu de "campo burocrático", para propor uma via media entre essas duas abordagens, que concebe o neoliberalismo como uma articulação entre Estado, mercado e cidadania, aparelhando o primeiro para impor a marca do segundo à terceira. Essa concepção repatria a penalidade para o centro da produção de um Estado-centauro, que pratica o laissez-faire no topo da estrutura de classes e o paternalismo punitivo na base

Palavras-CHAVE: Neoliberalismo. Governamentalidade. Campo burocrático. Estado penal. Política social. Bourdieu.
\end{abstract}

Há cerca de vinte anos, iniciei uma série de pesquisas de campo sobre a estrutura, a experiência e o tratamento político da pobreza urbana em sociedades avançadas, centrada no destino do gueto negro norte-americano, após o refluxo do movimento pelos Direitos Civis, e do definhamento das periferias operárias das metrópoles da Europa Ocidental, a exemplo da decadência das banlieues francesas do Cinturão Vermelho sob a pressão da desindustrialização. Realizei observação etnográfica em meio ao total abandono do histórico South Side de Chicago e nos abjetos projetos habitacionais de La Courneuve, tendo como pano de fundo a paisagem dual da Paris periférica. E lancei mão das ferramentas de comparação analítica para decifrar a ascensão de um novo regime de "marginalidade

* Professor de Sociologia da University of California, Berkeley e pesquisador do Centre Européen de Sociologie et de Science Politique, Paris.

Department of Sociology, 410 Barrow Hall - University of California, Berkeley, CA94720, USA. loic@berkeley.edu Tradução: Renato Aguiar. Revisão técnica: Anete Ivo e Sérgio Lamarão.

${ }^{1}$ Apresentado no Forum sobre neoliberalismo, na Social Anthropology (novembro, 2011 e março 2012), com respostas de Hilgers, A. Ong, J. Comaroff, e J. Peck, N.
Theodore, e N.Brenner [versão de 8 de dezembro de 2011]. avançada", impulsionada pela fragmentação do trabalho assalariado, pelo recuo do Estado social e pela disseminação do estigma territorial. Eu não tinha a menor noção de que essa pesquisa sobre a difícil situação dos Urban Outcasts [párias urbanos] do novo século (Wacquant, 2008a) me levaria das ruas do hipergueto às entranhas profundas do gigantesco sistema carcerário dos Estados Unidos e, dali, à controversa questão de neoliberalismo e da reestruturação do Estado numa escala global (Wacquant, 2009a). Neste artigo, recomponho brevemente esse percurso intelectual, desde a microetnografia do precariado ${ }^{2}$ pós-industrial até a macrossociologia do Leviatã neoliberal no começo do século, a fim de propor teses que apontem para uma antropologia histórica do neoliberalismo realmente existente.

Para elucidar os determinantes e as modalidades da marginalidade na metrópole norte-americana ao final do século XIX, tive de encontrar um caminho para contornar dois obstáculos epistemológicos cruciais: o mito intelectual

${ }^{2}$ Esse termo é um neologismo cunhado a partir da combinação de "precário" com "proletariado" [Nota do Revisor]. 
agregador da "subclasse", essa nova subcategoria do negro pobre que supostamente assola o centro da cidade, e o longevo tropo da "desorganização", herdada da escola ecológica de sociologia urbana (para críticas abrangentes dessas duas noções, ver Wacquant, 1996 e 1997). Para superá-los, realizei uma pesquisa de campo sobre as estratégias de vida de jovens afro-americanos em Woodlawn, uma parte do que restou da "Bronzeville" de Chicago (Drake; Cayton, [1945] 1993). Devido a uma série de circunstâncias narradas em outros lugares, tornei-me membro de uma academia local de boxe, aprendi a arte do pugilismo profissional e usei o clube como trampolim para arriscar-me nas vizinhanças (Wacquant, [2000] 2004) e reconstruir completamente minha compreensão do gueto. ${ }^{3}$

Recompondo as histórias de vida de meus parceiros de ringue, logo descobri que quase todos tinham passado pela cadeia ou cumprido pena de prisão. Assim, para dar sentido às suas trajetórias, tive que compreender o "grande salto penal para trás” que transformou os Estados Unidos de ponto de referência da penalidade progressista dos anos 1960 em líder mundial de encarceramento e exportador global de políticas agressivas de controle da criminalidade nos anos 1990 (Wacquant, 2009b). O mapeamento do boom carcerário dos Estados Unidos após 1973 deixou claro que a acelerada retração da política do welfare, que conduziu à infame "re- ções despossuídas e desonradas, desestabilizadas pela dissolução do pacto fordista-keynesiano e concentradas nos bairros abandonados da cidade polarizada; e que a colocação das frações marginalizadas da classe trabalhadora pós-industrial sob severa tutela, guiada por um behaviorismo moral, propicia um cenário teatral fundamental, no qual as elites governantes podem projetar a autoridade do Estado e sustentar os déficits de legitimidade a que estão sujeitas, sempre que renunciam às suas missões estabelecidas de proteção social e econômica.

Isso foi confirmado nos anos 1990, em toda a Europa Ocidental, quando uma sucessão de governos de esquerda elevou o combate à criminalidade de rua à posição de prioridade nacional, naquelas mesmas zonas urbanas onde intensificavam-se a insegurança social e a decadência espacial, juntamente com a normalização do desemprego e do emprego precário. Rastreando os percursos internacionais da política da "tolerância zero" e vários slogans penais e panaceias "made in USA" correlatos (a chamada teoria do crime da janela quebrada, sentenças mínimas compulsórias, campos correcionais de treinamento militar para jovens infratores, negociação de sentença etc.), descobriu-se, além disso, um padrão distintivo de difusão sequencial e de engrenagem funcional por meio do qual políticas de desregulamentação econômica, de workfare fiscalizador e de justiça criminal punitiva tendem a andar e a florescer juntas (Wacquant, 2011). Resumindo, a penalização da pobreza emergiu como um elemento central da implementação doméstica e da difusão através das fronteiras do projeto neoliberal, do "punho de ferro" do Estado penal, unido à "mão invisível" do mercado, ambas em conjunção com o esgarçamento da rede de seguridade social. O que começou como uma pesquisa sobre a situação cotidiana do precariado urbano no centro de Chicago e na periferia de Paris terminou, assim, como um desafio teórico sobre o caráter e os elementos constituintes do neoliberalismo em escala planetária.

berdade condicional, bases de dados de criminosos e sistemas variados de vigilância), no interior e nas proximidades dos bairros marginalizados, onde se aglomera o proletariado pós-industrial [Nota do Revisor]. 


\section{DOMÍNIO DO MERCADO E GOVERNAMENTALIDADE}

Como, então, essa peregrinação intelectual sugere que lidemos com a categoria fugidia, nebulosa e controversa do neoliberalismo - alguns dos seus analistas mais astuciosos o caracterizam como um "conceito maroto", em constante busca de especificidadee legitimidade analíticas? Embora Hilgers (2011) retrate a antropologia do neoliberalismo como organizada numa configuração triádica, formada pelas abordagens cultural, de governamen-talidade e sistêmica (para mapeamentos alternativos, ver também Hoffman et al. [2006] e Richland [2009]), eu a vejo como polarizada entre uma concepção econômica hegemônica, ancorada em variantes (neoclássicas e neomarxistas) de domínio de mercado, por um lado, e uma abordagem insurgente, alimentada por derivações frouxas da noção foucaultiana de governamentalidade, pelo outro. Essas duas concepções produziram agendas de pesquisa ricas e produtivas, mas que apresentam defeitos opostos: enquanto uma é excessivamente restrita, despojada de instituições, e beira o apologético ao tomar o discurso do neoliberalismo em seu valor nominal, a outra é excessivamente ampla e promíscua, superpovoada por uma proliferação de instituições, todas aparentemente infectadas pelo vírus neoliberal, e descamba para um solipsismo crítico. Para a primeira, o neoliberalismo é a imposição direta da economia neoclássica como modo supremo de pensamento, e do mercado como mecanismo ideal, ainda que inflexível, para organizar todas as trocas (e.g., Jessop, 2002; Saad-Filho; Johnston, 2005); para a última, trata-se de uma racionalidade política maleável e mutável, que se adapta a muitos tipos de regimes e se insinua em

6 "Desde os anos 1980, uma confusa mistura de alcance excessivo e ausência de especificação tem acompanhado a conturbada ascendência do conceito de neoliberalismo na economia política heterodoxa. O conceito tornou-se simultaneamente um ponto focal terminológico para debates sobre a trajetória das transformações regulatórias pós1980 e uma expressão dos profundos desacordos e confusões que caracterizam esses debates. Consequentemente, o 'neoliberalismo' tornou-se uma espécie de conceito maroto - promiscuamente difuso, até agora inconsistentemente definido, empiricamente impreciso e frequentemente contestado." (Brenner; Peck; Theodore, 2010, p. 183-184). todas as esferas da vida, sem nenhum fundamento externo consistente sobre o qual apoiar-se para oporse a ela (e.g., Barry; Osborne 1996; Brown, 2005). Curiosamente, essas duas concepções convergem para obscurecer o que é "neo" no neoliberalismo, a saber, a reengenharia e a reestruturação do Estado como principal agência que conforma ativamente as subjetividades, as relações sociais e as representações coletivas apropriadas a tornar a ficção dos mercados real e relevante.

A dominância da concepção econômica, ou melhor, economicista, do neoliberalismo está bem estabelecida (e.g., Campbell; Pedersen, 2001; Edelman; Haugerud, 2005; Gamble, 2006; Cerny, 2008). Para a grande maioria tanto dos defensores quanto dos críticos, o termo designa o ressurgente "império do capital", para evocar o título da reconstrução histórico-materialista de Ellen Meiksins (2005) da sucessão de projetos de base territorial, comerciais e capitalistas de domínio imperial, distinguindo-se esse último por buscar impor imperativos de mercado não só a todos os territórios, mas também a todas as atividades humanas. Essa visão reinante associa o neoliberalismo à ideia de "mercado autorregulador" e considera que o Estado está trancado numa relação de soma-zero e antagônica a ele. Lógica e historicamente, o advento do "fundamentalismo de mercado" implica a redução de despesas, a retirada ou a impugnação do Estado, descrito como um obstáculo à eficiência ou como mera instrumentalidade a serviço da promoção e da supremacia reconquistada do capital. Assim, de acordo com Colin Crouch (1997, p.358), a concomitância do declínio da classe operária manual e da ascensão do capital financeiro, a disseminação de novas tecnologias de comunicação e a liberalização dos fluxos econômicos através das fronteiras nacionais introduziram uma "forma de capitalismo de curto prazo, de puro mercado e livre de regulações".

Os "termos do consenso neoliberal" emergente incluem o "abandono universal das políticas keynesianas" e provocam "o esvaziamento do Estado e a privatização de um número cada vez maior de suas funções" (Crouch, 1997, p.357, 359). 
De modo semelhante, para David Harvey (2005, p.3-4), o "neoliberalismo é, em primeira instância, uma teoria de práticas políticas econômicas que propõe que o bem-estar humano pode ser alcançado mais plenamente pela emancipação das liberdades e competências empresariais individuais dentro de uma estrutura institucional caracterizada por direitos consistentes à propriedade privada, a mercados livres e ao livre comércio. O papel do Estado é criar e preservar uma estrutura institucional apropriada a tais práticas”. A virada para o neoliberalismo envolve a combinação triádica de "desregulamentação, privatização e retirada do Estado de muitas áreas de atuação”. Na prática, os Estados só se afastam do modelo doutrinário do "governo pequeno" para fomentar um clima propício de negócios em prol do empreendimento capitalista, para salvaguardar instituições financeiras e reprimir a resistência popular ao ímpeto neoliberal para com a “acumulação por espoliação".

Grande parte da antropologia doneoliberalismo consiste em transportar esse esquema a diferentes países do globo, ou levá-lo à escala continental, para capturar as armadilhas culturais do domínio do mercado e as reações sociais engendradas por ela (e.g., Camaroff; Camaroff, 2001; Greenhouse, 2009). A América Latina é favorita, seguida pelos países do bloco da ex-União Soviética e da África. Em seu relato abrangente Africa in the Liberal World Order [África na ordem liberal mundial], James Ferguson (2006, p. 11) caracteriza o neoliberalismo, de uma maneira geral, como a simultânea retração do Estado e extensão do mercado: "De acordo com a filosofia econômica do ‘neoliberalismo', apregoava-se que, removendo as 'distorções' do Estado aos mercados, poder-se-iam criar as condições para o crescimento econômico, ao mesmo tempo que a rápida privatização traria um fluxo de novos investimentos de capital privado”. Essa noção equivale às medidas econômicas de "ajuste estrutural”, "que supostamente fariam Estados opressivos e autocráticos recuarem e liberariam uma nova 'sociedade civil' vital, que seria não só mais democrática e economicamente como também mais eficiente.” (Ferguson, 2006, p. 38-39). Trata-se de um termo-invólucro, que aponta para as mudanças sociais produzidas, a obstinada resistência popular e as adaptações cotidianas dos programas de austeridade e privatização também conhecidos como "O consenso de Washington” (Williamson, 1993).

Em contraste com essa visão "ordenada" do neoliberalismo como um todo coerente, senão monolítico, os estudiosos da governamentalidade propõem uma visão “desordenada” do neoliberalismo, como uma miscelânea de noções, estratégias e tecnologias de cálculo destinadas a moldar populações e pessoas. ${ }^{7}$ Através dessa ótica, o neoliberalismo não é uma ideologia econômica ou um pacote de políticas, mas uma "normatividade generalizada”, uma "racionalidade global" que "tende a estruturar e organizar não apenas as ações de governo, mas também a conduta dos próprios governados" e até mesmo a sua autoconcepção, segundo os princípios de competição, eficiência e utilidade(Dardot;Laval, 2007, p.13). Estudiosos da governamentalidade insistem que os mecanismos de governo não estão situados no Estado, mas circulam em toda a sociedade, assim como através das fronteiras nacionais. Consequentemente, eles trabalham transversalmente para rastrear a disseminação e a concatenação de técnicas de "condução de condutas" através de múltiplos lugares de autoprodução, incluindo o corpo, a família, a sexualidade, o consumo, a educação, as profissões, o espaço urbano etc. (Larner, 2000). Eles também gostam de salientar a contingência, a especificidade, a multiplicidade, a complexidade e as combinações interativas (tornadas prodigiosas pelo novo bordão de coloração

Essa visão deriva de textos de Foucault e de um ciclo de conferências, ministrado em 1978-1979, no Collège de France, sobre The Birth of Biopolitics [O nascimento da biopolítica] (Foucault 2004), o qual inspirou um programa de pesquisa geral sobre "governamentalidade" como a arte de moldar populações (sujeição) e o self (subjetivação). Os termos "governança pós-social”, "liberal avançado" e "liberal tardio" são frequentemente usados como sinônimos de neoliberal (para uma visão geral, ver Dean [1999] e para uma defesa paradoxal de uma abordagem teórica que nega a si mesma como tal, ver O’Malley, Rose e Valverde [2006]). Não há espaço aqui para tratar dos problemas presentes nas próprias formulações de Foucault de governamentalidade e neoliberalismo (a começar por seu matiz idealista), e de elas se combinarem, nem, muito menos para avaliar as suas derivações e a sua relevância para as mudanças históricas que se sucederam após a morte de Foucault. 
deleuziana, “assemblage” [montagem]): não há um Neoliberalismo com "N" maiúsculo, mas um número indefinido de neoliberalismos com " $\mathrm{n}$ " minúsculos, oriundos da hibridização de práticas e ideias neoliberais em curso com as condições e formas locais. Essa abordagem é levada ao extremo por Aihwa Ong, em sua prestigiada coleção de ensaios Neoliberalism as Exception [Neoliberalismo como exceção] na Ásia Oriental, na qual ela propõe o "estudo do neoliberalismo, não como uma 'cultura' ou uma 'estrutura', mas como técnicas de cálculo móveis de governo que podem ser descontextualizadas de suas fontes originais e recontextualizadas em constelações de relações reciprocamente constitutivas e contingentes" (Ong, 2007, p. 13).

O impulso analítico de ampliar para além do Estado e abranger domínios institucionais é frutífero, como o é a noção de que a neoliberalização é um processo produtivo, em vez de essencialista, que transborda da economia. No entanto, é problemático situar esse processo na migração de tecnologias "maleáveis" de conduta que, quando transplantadas, são constantemente "realinhadas" e "em mutação". Primeiro, não está claro o que torna uma tecnologia de conduta neoliberal, mas certamente, técnicas burocráticas - tais como auditorias, indicadores de desempenho e parâmetros de referência (prediletas da antropologia neofoucaltiana do neoliberalismo) - podem ser usadas para apoiar ou fomentar outras lógicas, assim como o fazem as técnicas atuariais. Da mesma forma, não há nada a respeito de normas de transparência, responsabilidade de prestação de contas e eficiência que as torne incentivos necessários à mercadorização; na China, por exemplo, elas foram introduzidas no intuito de perseguir metas patrimoniais e reinscrever ideais socialistas (Kipnis, 2008). O problema com a abordagem da governamentalidade é que a sua caracterização operacional do neoliberalismo como "governar através do cálculo” (Ong, 2007, p. 4) é tão desprovida de especificidade que o torna coetâneo com qualquer regime minimamente competente, ou com as forças de racionalização e individualização carac- terísticas da modernidade ocidental in globo. ${ }^{8}$ Por último, como as tecnologias de conduta são “migrantes" e "mutantes", o neoliberalismo estaria, ao mesmo tempo, em toda a parte e em lugar nenhum. Ele abrange o processo todo e sem conteúdo, consistindo numa forma fluida, sem substância, padrão ou direção. No final, portanto, a escola da governamentalidade nos dá uma concepção do neoliberalismo exatamente tão pobre quanto aquela proposta pela ortodoxia econômica que pretende contestar.

\section{O NEOLIBERALISMO COMO ESTADO GERENCIAL QUE ADAPTAA SOCIEDADEAO MERCADO}

Proponho traçar uma via media entre esses dois polos, uma via que reconheça - desde a sua incubação intelectual pelo Colóquio Lippman em Paris, em 1938, e o "coletivo de pensamento" transnacional ancorado pela Société du MontPélerin após 1947 (Denord, 2007), até suas várias encarnações históricas durante as últimas décadas do século XX, e a sua reafirmação paradoxal após a crise financeira de 2008 - que o "neoliberalismo sempre foi um projeto em aberto, plural e adaptável" (Peck, 2008, p. 3), mas que, todavia, possui um núcleo institucional que o torna distinto e reconhecível. ${ }^{9}$ Esse núcleo consiste numa articulação entre Estado, mercado e cidadania que apare-

${ }^{8}$ Se o neoliberalismo é uma seleção de "tecnologias calculistas" oriundas da economia e que migraram para outros domínios da vida social, então seu nascimento data de 1494, com a invenção do livro contábil de dupla entrada (Carruthers; Espeland, 1991), e o grande teórico do neoliberalismo não é Ludwig von Mises, Friedrich von Hayek nem Milton Friedman, mas Max Weber ([19181920] 1978, p.85-113, 212-226), para quem a supremacia da racionalidade instrumental separou o Ocidente do restante do mundo - e com mais razão, se considerarmos que Weber dá grande ênfase à noção correlata de Lebensfürung, “conduta de vida”, em sua sociologia comparativa da religião.

${ }^{9}$ Trata-se de uma exigência lógica: para que diversificadas espécies locais de neoliberalismo emerjam mediante "mutação", é preciso que haja um gênero comum do qual todas derivem. Segue-se que toda e qualquer concepção de múltiplos “neoliberalismos com 'n' minúsculo" pressupõe, necessariamente, algum "neoliberalismo com 'N' maiúsculo", mesmo que implicitamente; e toda e qualquer ocorrência periférica e parcial do fenômeno só poderá ser caracterizada como tal em referência, aberta ou encoberta, a um núcleo original mais completo. 
lha o primeiro para impor a marca do segundo à terceira. São essas três instituições que devem ser consideradas no nosso âmbito analítico. Discordo das concepções de neoliberalismo centradas no mercado, pois priorizo meios (políticos) sobre fins (econômicos), mas renuncio à perspectiva da governamentalidade, pois priorizo a reestruturação do Estado às tecnologias e à lógica não estatal; meu foco é saber como o Estado efetivamente redesenha as fronteiras e o caráter da cidadania através de suas políticas adaptadas ao mercado. Por consequência, recomendo que efetuemos uma tripla reorientação para dar suporte à antropologia do neoliberalismo, compreendida não como uma doutrina econômica invasiva ou como a migração de técnicas de governo, mas como uma constelação política concreta: de uma concepção econômica “pobre”, centrada no mercado, para uma concepção sociológica "densa”, centrada no Estado, que especifica o mecanismo institucional envolvido no estabelecimento da dominância de mercado e seu impacto operante sobre a efetiva adesão social dos membros da sociedade. Sustento que o conceito pouco conhecido de Bourdieu ([1993] 1994) de campo burocrático oferece uma ferramenta flexível e poderosa para compreender a reconstrução do Estado como máquina de estratificação e classificação, que está orientando a revolução neoliberal a partir de cima. Essa reorientação pode ser explicada em detalhe em três teses.

Tese 1: O neoliberalismo não é um projeto econômico, mas sim político; ele envolve não o desmantelamento do Estado, mas a sua reengenharia. Isso se deve a três razões básicas. Primeiro, os mercados em toda parte são e sempre foram criações políticas: eles são sistemas de trocas baseados no preço, com regras que devem ser estabelecidas e arbitradas por autoridades políticas rigorosas e apoiadas em mecanismos legais e administrativos amplos, os quais, na era moderna, equivalem a instituições estatais (Polanyi [1957] 1971; Fligstein, 1996; Macmillan, 2003). Segundo, como é demonstrado pela história social e elaborado pela teoria social corrente, desde Émile
Durkheim e Marcel Mauss até Karl Polanyi e Marshall Sahlins, relações sociais e construtos culturais sustentam necessariamente intercâmbios econômicos, e as pessoas negociam normalmente sob as sanções do mercado: o Estado deve, portanto, intervir para superar as oposições e controlar as estratégias de evasão. Terceiro, a historiografia produzida pelo transnacional Geistkreis ${ }^{10}$ [The Mind Circle] explicita que, desde as suas origens na crise dos anos 1930, o neoliberalismo se empenhou não em restaurar o liberalismo do final do século XIX, mas em superar a equivocada concepção de Estado deste último (Denord, 2007; Mirowski; Plehwe, 2009). O neoliberalismo se origina de uma dupla oposição: por um lado, às soluções coletivistas (primeiro socialistas e, depois, keynesianas) para os problemas econômicos; e, por outro, à visão minimalista e negativa do "Estado vigilante" do liberalismo clássico. Ele almeja reformar e redirecionar o foco do Estado de modo a fomentar e apoiar ativamente o mercado como uma criação política em curso. ${ }^{11}$

Emoutrotrabalho, caracterizeiesta reengenharia neoliberal como a articulação de quatro lógicas institucionais (Wacquant, 2010a):

(i) a mercadorização como extensão do mercado ou de mecanismos característicos do mercado,

${ }^{0}$ O Geistkreis foi um seminário informal, fundado por Friedrich Hayek e Herbert Furthin no começo dos anos 1920, Os membros do grupo reuniam-se em Viena uma ou duas vezes por mês para discutir textos de diferentes áreas do conhecimento (matemática, ciências naturais, sociologia, história, filosofia, arte, literatura, neurociência, economia etc.). Os encontros se estenderam até 1938 [Nota do Revisor].

${ }^{11}$ Esse ponto é enfatizado por François Denord (2007), e por Jamie Peck (2009, p. 3), que desenterra um antigo e pouco conhecido texto de Milton Friedman (publicado em 1951, apenas em sueco) no qual o economista de Chicago explica: "O erro fundamental na fundação do liberalismo do século XIX [foi que ele] confiou ao Estado outras tarefas penosas, além de manter a paz e prever que os contratos fossem cumpridos. Era uma ideologia ingênua. Considerou que o Estado só podia prejudicar [e que] o laissez-faire tinha que ser a regra". Contrária a essa visão, a "doutrina [do] neoliberalismo" afirma que "há funções verdadeiramente positivas destinadas ao Estado”, entre elas garantir direitos de propriedade, impedir monopólios, garantir a estabilidade monetária e (o mais notável), "aliviar a pobreza severa e o infortúnio". Peck (2009, p. 9) está correto ao observar que o "neoliberalismo, em suas várias aparências, sempre tratou de capturar e reutilizar o Estado no interesse de moldar uma ordem de mercado pró-corporações e livre comércio", mas não chega a conceber a dimensão endógena dos meios institucionais recorrentes mediante os quais o Estado levaria a cabo essa moldagem. 
baseada na noção de que tais mecanismos são meios universalmente ideais para alocação eficiente de recursos e recompensas;

(ii) políticas sociais disciplinadoras, com a passagem do welfare protetor, concedido incondicionalmente como questão de direito, para o workfare corretivo, sob o qual a assistência social é condicionada a empregos flexíveis e implica o cumprimento de comportamentos específicos (treinamento, testes, procura de emprego e trabalho, mesmo por salários abaixo da linha de pobreza, mas também controle da natalidade, cumprimento de leis etc.);

(iii) políticas penais extensivas e obscenas, com o objetivo, por um lado, de controlar as desordens geradas pela difusão da insegurança social nas áreas urbanas impactadas pelo trabalho flexível e, por outro, de representar a soberania do Estado na estreita janela da vida cotidiana, que ele agora afirma controlar.

(iv) o tropo da responsabilidade individual como discurso motivacional e cimento cultural que unifica esses vários componentes da atividade do Estado.

Essa concepção vai além da perspectiva do domínio do mercado, na medida em que outorga um papel dinâmico ao Estado em todas as quatro frentes: econômica, social, penal e cultural. Para considerar apenas as duas primeiras, o Estado re-regula ativamente - em vez de "desregular" - a economia em favor das empresas (Vogel, 1996), e dedica-se a amplas medidas "corretivas" e "construtivas" para apoiar e expandir os mercados (Levy, 2006) para empresas, produtos e trabalhadores, indistintamente. Na frente social, os programas governamentais impõem obrigações onerosas aos beneficiários de assistência social e buscam ativamente retificar seus comportamentos, reformar sua moral e orientar suas escolhas de vida através de uma mescla de doutrinação, supervisão burocrática e persuasão material (Hays, 2003), transformando o apoio social em vetor de disciplina e o direito ao desenvolvimento pessoal em obrigação de trabalhar em empregos precários (Moreira, 2008). Essa concepção compacta do neoliberalismo como or- ganização quadrúpede também provê rígidos conteúdos institucionais à noção difusa de "racionalidade política" evocada pelos foucaultianos, pois especifica os meios empregados pelo Estado para ampliar e sustentar a mercadorização face à relutância pessoal e ao esquivamento ou oposição coletivos.

\section{Tese 2: O neoliberalismo implica uma propensão} para a direita do campo burocrático e engendra um Estado-centauro. Se o Estado não se "retirou" ou" se esvaziou", mas, com efeito, foi reconstruído e reestruturado, como devemos compreender essa reforma?É aqui que o conceito de Bourdieu ([1993] 1994) de campo burocrático - construído como um conjunto de organizações que monopolizam com sucesso a definição e a distribuição de bens públicos - se mostra crucial. ${ }^{12}$ A maior virtude dessa noção, construída minuciosamente através de uma análise histórica da transição multissecular do modo de reprodução dinástico para o modo de reprodução burocrático do poder e ancorada na potência crescente do capital cultural institucionalizado (ver Bourdieu, 2012) é a de nos lembrar que "o Estado" não é um monólito, um ator coerente (opere ele autonomamente ou como um servo diligente dos dominantes), nem uma alavanca única, sujeita a ser capturada por interesses específicos ou movimentos emergentes da sociedade civil. Pelo contrário, ele é um espaço de forças e de lutas sobre o contorno, as prerrogativas e as prioridades da autoridade pública, e, em particular, sobre os "problemas sociais" que merecem

${ }^{12}$ Campo burocrático é um dos três conceitos forjados por Bourdieu para repensar a posição de governo; ele não deve ser confundido com o campo político (com o qual faz interseção), nem com o campo do poder (no qual está situado). Ver Wacquant (2005, p.13-18), para uma explicação das relações entre eles, e Wacquant (2010a), para uma reelaboração do conceito de campo burocrático voltado para especificar o caráter do Estado neoliberal. Na perspicaz caracterização de Mudge (2008, p. 705), o neoliberalismo tem três faces, a intelectual (uma doutrina), a burocrática (políticas estatais de liberalização, desregulação, privatização, despolitização e monetarismo), e a política (lutas pela autoridade do Estado), as quais "compartilham um núcleo comum e característico: a elevação do mercado acima de todos os demais modos de organização”. Ela, porém, atribui um fardo analítico insustentável ao campo político, em vez de mostrar o campo burocrático como o principal local no interior do qual é travada a batalha sobre as missões e os meios da ação pública. 
sua atenção e como eles devem ser tratados.

Bourdieu ([1993] 1998) sugere ainda que o Estado contemporâneo é atravessado por duas batalhas internas e homólogas aos conflitos que perturbam obliquamente o conjunto do espaço social: a batalha vertical (entre dominantes e dominados), que opõe a "alta nobreza do Estado" dos formuladores de política entusiastas das noções neoliberais, que querem fomentar a "mercatização", à "baixa nobreza estatal" dos executores, que defendem as missões protetoras da burocracia pública; e a batalha horizontal (entre as duas modalidades de capital, a econômica e a cultural, competindo pela supremacia interna), que envolve a "mão direita" do Estado, a ala econômica, que pretende impor restrições fiscais e a disciplina de mercado, e a "mão esquerda" do Estado, a ala social, que protege e apoia as categorias destituídas de capital econômico e cultural. Em Punishing the Poor, adapto esse conceito para introduzir, em uma única estrutura analítica, as mudanças punitivas ocorridas nas políticas de bem-estar e penais, as quais convergiram para estabelecer a "dupla regulação" da marginalidade avançada através do workfare fiscalizador e do prisonfare penalizador. E acrescento o braço da justiça criminal - a polícia, os tribunais, a prisão e suas extensões: suspensão condicional da pena, liberdade condicional, bancos de dados judiciais, obrigações civis e burocráticas vinculadas a sanções criminais etc. - como um componente central da mão direita do Estado, juntamente com o Tesouro e o Ministério da Fazenda (Wacquant, 2009a, p.3-20, 304-313).

Usando esse esquema, pode-se fazer um diagrama do neoliberalismo como o vaivém sistemático das prioridades e ações estatais da mão esquerda para a mão direita, isto é, do polo protetor (feminino e coletivizante) para o polo disciplinador (masculino e individualizante) do campo burocrático. Isso se dá através de dois caminhos distintos, mas complementares: (i) a transferência de recursos, programas e populações da ala social para a ala penal do Estado (como ocorre quando pacientes doentes são "desinstitucionalizados” com o fechamento de hospitais e "reinstitucionalizados" em cadeias e prisões depois de transitarem como sem-teto); (ii) a colonização da assistência social, da saúde, da educação, da habitação de baixa renda, dos serviços de assistência à infância, etc. por técnicas panópticas e disciplinares e pelos tropos da mão direita (como ocorre quando os hospitais privilegiam as preocupações orçamentárias sobre as médicas em sua organização interna e quando as escolas colocam a redução da evasão juvenil e da violência em sala de aula à frente da pedagogia, contratando seguranças em vez de psicólogos). Essa dupla inclinação direitizante da estrutura e das políticas do Estado não é, enfaticamente, produto de algum imperativo sistêmico misterioso ou de necessidade funcional irresistível; trata-se do resultado (estruturalmente condicionado, mas historicamente contingente) de lutas materiais e simbólicas, travadas dentro e fora do campo burocrático, sobre as responsabilidades e modalidades de operação da autoridade pública (Wacquant, 2009a, p.19-20, 67-69, 108-9, 312-3). Disso decorre que a velocidade, a magnitude e os efeitos dessa torção institucional irão variar de país para país, dependendo de sua posição na ordem internacional, da constituição (física e moral) do seu campo nacional de poder e da configuração do seu espaço social e das suas divisões culturais.

Como resultado dessa inclinação “direitizante, o Leviatã neoliberal não se parece nem com o Estado minimalista do liberalismo do século XIX, nem com o Estado evanescente igualmente lamentado pelos críticos econômicos e da governamentalidade do neoliberalismo, mas sim com um Estado-centauro, que exibe rostos opostos nos dois extremos da estrutura de classes: ele é edificante e 'libertador' no topo, onde atua para alavancar os recursos e expandir as opções de vida dos detentores de capital econômico e cultural; mas é penalizador e restritivo na base, quando se trata de administrar as populações desestabilizadas pelo aprofundamento da desigualdade e pela difusão da insegurança do trabalho e da inquietação étnica. Oneoliberalismo realmente existente exalta o "laissez faire et laisez passer" para os dominantes, mas se mostra paternalista e intruso para com os subalternos, especialmente para com o 
precariado urbano, cujos parâmetros de vida ele restringe através da malha combinada de workfare fiscalizador e da supervisão judicial.

Tese 3: $\mathrm{O}$ crescimento e a glorificação do braço penal do Estado constituem um componente essencial do Leviatã neoliberal. Presos à visão ideológica, que o descreve como introdutor do fim do "governo grande", os analistas sociais do neoliberalismo negligenciaram a formidável reabilitação e a estupenda expansão do aparato penal do Estado que acompanhou a onda do domínio do mercado. Desmentindo as profecias feitas entre 1945 e 1975 por especialistas do direito penal e igualmente por teóricos radicais da punição, de que se tratava de uma organização desacreditada e fadada a definhar até desaparecer (Tonry, 2004), a prisão fez um retorno espetacular à vanguarda institucional de um lado ao outro do Primeiro e do Segundo mundos ao longo das últimas três décadas. Com poucas, parciais e preciosas exceções (Canadá, Alemanha, Áustria e partes da Escandinávia), o encarceramento cresceu rapidamente em todas as sociedades pós-industriais do Ocidente, inchou nas nações pós-autoritárias da América Latina e explodiu nos Estados-nação oriundos do colapso do bloco soviético, à medida que faziam sua transição de economia de comando para a de mercado. O estoque carcerário não se limitou a crescer rapidamente em todas as três regiões (Walsmsley, 2011), juntamente com a precarização do trabalho e a redução da assistência social; ele está em toda parte, composto desproporcionalmente por pobres urbanos, párias étnicos e nacionais, populações sem-teto e doentes mentais abandonados, e por refugos variados do mercado de trabalho (Wacquant, 2009a, p. 69-75).

O persistente crescimento da população carcerária é, além do mais, apenas uma manifestação crua e explícita da expansão e da exaltação do Estado penal na era do mercado triunfante. Outros indicadores incluem o aparelhamento ostensivo da polícia dentro e em torno das áreas relegadas e o aumento dos recursos destinados aos tribunais para lidar com o comportamento rebelde ou com os pequenos delitos; a ampliação da rede judicial mediante sanções alternativas, esquemas de controle pós-custódia e o desenvolvimento exponencial de bancos de dados digitalizados da justiça; a proliferação de centros de retenção administrativa para confinar e expulsar migrantes irregulares; a hiperatividade dos legisladores na frente criminal (eles multiplicaram e endureceram as sanções penais a uma velocidade jamais testemunhada) e o boom de um setor da mídia que negocia imagens catastróficas do perigo criminal; a promoção da luta contra o crime nas ruas ao topo da agenda de governo (ao mesmo tempo em que os delitos empresariais eram ativamente descriminalizados) $\mathrm{e}$ a proeminência da questão da "insegurança" nas campanhas eleitorais; e a submissão da política penal a parâmetros emotivos e simbólicos, em aberta desconsideração da expertise penológica.

O fortalecimento e a ampliação do setor penal do campo burocrático não são uma resposta à criminalidade, a qual declinou no Ocidente ao longo das últimas duas décadas e geralmente flutua sem conexão com os níveis e as tendências da punição (Young; Brown, 1993; Lappi-Sepälä, 2011). Tampouco seriam a cria do advento da "sociedade exclusiva", a ascensão de uma "cultura de controle", o declínio da confiança no governo, o acatamento da "sociedade de risco" ${ }^{13} \mathrm{e}$ nem, muito menos, a criatura de especuladores sedentos de lucro, como na demonologia militante do "complexo industrial-carcerário” (Wacquant, 2010b). O inchamento da instituição penal é um tijolo no edifício do Leviatã neoliberal. É por isso que ela está estreitamente correlacionada, não à onda de "ansiedades ontológicas" da "modernidade tardia", mas às mudanças específicas de fortalecimento do mercado nas políticas econômicas e sociais que desencadearam a desigualdade de classe, aprofundaram a marginalidade urbana e alimentaram o ressentimento étnico, ao mesmo tempo em que erodiram a legitimidade dos formuladores de políticas. Ao examinar tendências em uma dúzia

${ }^{13}$ Conforme proposto, respectivamente, por Jock Young (2000), John Pratt (2007) e Jonathan Simon (2007), para sinalizar as principais macroteorias opostas da mu-
dança penal recente. 
de sociedades avançadas, distribuídas entre quatro tipos de economias políticas, Cavadino e Dignan (2006, p. 450) relatam "uma propensão geral a mudanças nos níveis de punição desses países ao longo do tempo, [adequadas] ao mesmo padrão": "à medida que a sociedade se desloca rumo ao neoliberalismo, sua punição se torna mais severa”. Reelaborando esses mesmos dados a partir de um ângulo diferente, Lacey (2008, p.111) revela, a despeito de seu desejo de enfraquecer a tese da convergência penal, que o melhor prognóstico da taxa de encarceramento nesses países é o "grau de coordenação" da economia, isto é, um índice inverso àquele da neoliberalização.

A análise estatística de Lappi-Seppälä (2011, p. 300) de trinta países europeus confirma que a moderação penal encontra as suas raízes numa "cultura política consensual e corporativista, em níveis elevados de confiança social e de legitimidade política, e num Estado do bem-estar social forte", isto é, em características sociopolíticas antinômicas ao neoliberalismo. Além disso, o padrão temporal e geográfico de difusão da penalidade punitiva e obscena no globo acompanha as pegadas da difusão das políticas de desregulação e welfare disciplinador (Wacquant, 2009a, 2011). Não foi por acaso que os Estados Unidos se tornaram superpunitivos depois de meados dos anos 1970, exatamente quando o trabalho se precarizou, o suporte do welfare recuou,

nesse ponto que divirjo de Berard Harcourt (2011), que situa as raízes dessa conexão na invenção setecentista dos mitos combinado do "livre mercado" e da "polícia diligente". Eu vejo o Estado penal expansivo como uma criação distinta do neoliberalismo e não como uma herança ou um ressurgimento do liberalismo clássico. Ele surge após o período fordista-keynesiano porque esse último alterou decisivamente os parâmetros institucionais da atividade do Estado e as expectativas penal foi implantado nos países que empreenderam a rota neoliberal porque prometia resolver dois dilemas que a mercadorização cria para a manutenção da ordem social e política: (1) a restrição aos deslocamentos crescentes causados pela normalização da insegurança social na base da estrutura de classe e da estrutura urbana; e (2) a restauração da autoridade da elite governante, ao reafirmar "a lei e a ordem" apenas quando essa autoridade está sendo solapada pelos fluxos acelerados de dinheiro, capital, comunicações e pessoas através das fronteiras nacionais, bem como pela compressão da ação estatal por órgãos supranacionais e pelo capital financeiro. O conceito de campo burocrático ajudanos a capturar essa missão geminada da punição, à medida que nos leva a prestar igual atenção ao momento material e ao momento simbólico da política pública - no caso, ao papel instrumental de disciplinamento de classe e à missão comunicativa de projetar a soberania que a justiça criminal assume. ${ }^{15}$ Ele também nos convida a mudar de uma concepção repressiva da penalidade para uma concepção produtiva, que enfatiza a sua qualidade performática (Wacquant, 2008b), de modo que possamos perceber que os orçamentos e efetivos aumentados e a precedência dada ao policiamento e aos órgãos judiciais, em todas as sociedades transformadas pelo neoliberalismo enquanto programa econômico, não são uma heresia, uma anomalia e nem um fenômeno transitório, mas componentes essenciais do Estado neoliberal.

Para fazer avançar a antropologia do neoliberalismo conforme ele realmente evoluiu nos países onde plantou raízes - em oposição à forma como ele mesmo se descreve (o modelo do domínio do mercado), ou à forma como ele se dissipa quando não logra se cristalizar num regime coerente (o modelo da governamentalidade) -, deve-

coletivas vigentes sobre ele (para mais elaborações, ver Wacquant, 2009a, p.227-228).

${ }^{15}$ Decorre daí que, para conceituar adequadamente o Estado penal, não devemos apenas repatriar a justiça criminal ao núcleo da antropologia política. Devemos também pôr um fim à hostilidade recíproca (ou ignorância deliberada) existente entre as duas correntes da criminologia, a marxista e a durkheimiana, que elaboraram a lógica material e simbólica da punição de forma isolada e até em oposição uma à outra. 
mos reconhecer que ele é intrínseco ao registro da formação estatal. De modo muito parecido à maneira pela qual o "longo século XVI" viu nascer o Leviatã moderno na Europa Ocidental (Ertman, 1997), inclusive a invenção do socorro ao pobre e a prisão penal, como parte da dura transição do feudalismo ao capitalismo mercantilista, a virada do nosso próprio século testemunhou a remodelagem de um novo tipo de Estado, que reivindica sacralizar o mercado e abraçar a liberdade, mas, na realidade, reserva o liberalismo e seus benefícios àqueles que estão no topo, enquanto impõe o paternalismo punitivo àqueles que estão na base. Ao invés de ver a polícia, o tribunal e a prisão como apêndices técnicos da luta contra a criminalidade, devemos reconhecer que eles constituem as competências políticas centrais através das quais o Leviatã governa o espaço físico, recorta o espaço social, dramatiza as divisões simbólicas e encena a soberania. E, por isso, devemos trazê-los para o centro de uma antropologia política de governo renovada, capaz de capturar como o Estado identifica e administra territórios e categorias problemáticas, em sua busca de construir mercados e moldar cidadãos que se conformem a eles, quer desejem ou não.

Agradecimentos: Este artigo nasceu da discussão que se seguiu à minha intervenção inicial na conferência sobre "Marginalidade, penalidade e divisão étnica nas cidades na era do neoliberalismo triunfante: jornada de estudos em torno de Loïc Wacquant", Universidade Livre de Bruxelas (Bruxelas, 15 de outubro de 2010). Sou grato a Mathieu Hilgers, ao Laboratório de Antropologia dos Mundos Contemporâneos, ao Instituto de Sociologia e ao Grupo de Estudo sobre o Racismo, as Migrações e a Exclusão, por um animado dia de debates; a Aaron Benavidez, pelo excelente trabalho de pesquisa e suporte bibliográfico; e a Megan Comfort, por suas perspicazes sugestões analíticas e editoriais.

Texto recebido em 9 de dezembro de 2011 Aceito em 6 de fevereiro de 2012

\section{REFERÊNCIAS}

BARRY, Andrew; OSBORNE, Thomas; ROSE, Nikolas (Ed.) Foucault and political reason: liberalism, neoliberalism, and rationalities of government. Chicago: University of Chicago Press, 1996.

BOURDIEU, Pierre. Rethinking the state: on the genesis and structure of the bureaucratic field. Sociological Theory, [S.l.], Wiley-Blackwell, v.12, n.1, mar. p.1-19. [1993] 1994.

The abdication of the state. In: .The weight of the world: social suffering in contemporary society. Cambridge, UK: Polity Press, [1993] 1998. p.181-188.

2012

Sur l'état. Paris: Seuil e Raisons d'Agir Editions,

BRENNER, Neil; PECK, Jamie; THEODORE, Nik Variegated neoliberalization: geographies, modalities, Pathways. Global Networks, [S.1.], v.10, n. 2, abril, p. 82-222, 2010.

BROWN, Wendy. Neoliberalism and the end of liberal democracy. In: . Edgework: critical essays on knowledge and politics. Princeton: Princeton University Press, 2005. p. 37-59.

CAMPBELL, John; PEDERSEN, Ove (Ed.) The Rise of neoliberalism and institutional analysis. Princeton, NJ: Princeton University Press, 2001.

CAVADINO, Michel; DIGNAN, James. Penal policy and political economy. Criminology and Criminal Justice Review, Londres, Sage, v.6, n. 4, nov. p. 435-456, 2006.

CARRUTHERS, Bruce G.; ESPELAND, Wendy Nelson. Accounting for rationality: double-entry bookkeeping and the rhetoric of economic rationality. American Journal of Sociology, Chicago, University de Chicago Press, v. 97, n.1, jul, p.31-69, 1991.

CERNY, Philip G. Embedding neoliberalism: the evolution of a hegemonic paradigm. The Journal of International Trade and Diplomacy, Londres, v. 2, n. 1, primavera, p.146. 2008.

COMAROFF, Jean; COMAROFF, John L. (Ed.) Millennial capitalism and the culture of neoliberalism. Durham: Duke University Press, 2001.

CROUCH, Colin. The terms of the neoliberal consensus. The Political Quarterly. Columbia, University Faculty of Policial Science, v.68, n. 4, p. 352-360, 1997.

DARDOT, Pierre; LAVAL, Christian. La nouvelle raison du monde. Essai sur la société néolibérale. Paris: La Découverte, 2007.

DEAN, Mitchell. Governmentality: power and rule in modern society. Sage: Londres, 1999.

DENORD, François. Néo-libéralisme version française. Histoire d'une idéologie politique. Paris: Démopolis, 2007.

DRAKE, St. Clair; CAYTON, Horace. Black metropolis: a study of negro life in a northern city. Chicago: University of Chicago Press, [1945, 1962, 1969] 1993.

EDELMAN, Marc; HAUGERUD Angelique (Ed.) The anthropology of development and globalization: from classical political economy to contemporary neoliberalism. Cambridge: Wiley-Blackwell, 2005.

ERTMAN, Thomas. Birth of the Leviathan: building states and regimes in medieval and early modern Europe. Cambridge: Cambridge University Press, 1997.

FERGUSON, James. Global Shadows: Africa in the neoliberal world order. Durham, NC: Duke University Press, 2006.

FLIGSTEIN, Neil. Markets as politics: a political-cultural 
approach to market institutions. American Sociological Review, Nova York, v. 61, n. 4, ago. p. 656-673, 1996.

FOUCAULT, Michel. Naisssance de la biopolitique. Cours au Collège de France, 1978-1979. Paris: Seuil/Gallimard, 1978.

GAMBLE, Andrew. Neoliberalism. Capital \& Class, Londres, n.75, p. 127-34, 2001

GARLAND, David. The Culture of control: crime and social order in contemporary society. Chicago: University of Chicago Press. 2001.

GREENHOUSE, Carol J. (Ed.) Ethnographies of neoliberalism. Filadélfia: University of Pennsylvania Press, 2009.

HARCOURT, Bernard E. The illusion of free markets punishment and the myth of the natural order. Cambridge: Harvard University Press, 2011.

HARVEY, David. A brief history of neoliberalism. Nova York: Oxford University Press, 2005.

HAYS, Sharon. Flat broke with children: women in the age of welfare reform. Nova York: Oxford University Press, 2003.

HILGERS, Mathieu. The three anthropological approaches to neoliberalism. International Social Science Journal, Nova York, v. 61, n. 2 p. 351-364, 2011.

HOFFMAN, Lisa; DEHART, Monica; COLLIER, Steven J. Notes on the anthropology of neoliberalism. Anthropology News, Nova York, v. 47, n. 6, set., p. 9-10, 2006.

JESSOP, Bob. Liberalism, neoliberalism, and urban governance: a state-theoretical perspective. Antipode 34 Oxford, n.3, julho, p.452-472, 2002.

KIPNIS, Andrew B. Audit cultures: neoliberal governmentality, socialist legac $\mathrm{y}$, or technologies of governing? American Ethnologist, v.35, n.2, may, p.275289, 2008.

LACEY, Nicola. The prisoners' dilemma: political economy and punishment in contemporary democracies. Cambridge: Cambridge University Press, 2008.

LAPPI-SEPPÄLÄ, Tapio. Explaining imprisonment in Europe. European Journal of Criminology, Oxford, v. 8 , n.4, julho, p.303-328, 2011.

LARNER, Wendy. Neo-liberalism: policy, ideology, governmentality. Studies in Political Economy, Nova York, n. 63,2000

LEVY, Jonah D. (Ed.) The State after Statism: New State Yities in the Age of Liberalization. Cambridge, MA:

MCMILLAN, John. Reinventing the bazaar: a natura history of markets. Nova York e Londres: W.W. Norton, 2002. dres: Verso, 2003.
ONG, Aihwa. Neoliberalism as exception: mutations in citizenship and sovereignty. Durham: Duke University Press Books, 2006.

Neoliberalism as a mobile technology. Transactions of the Institute of British Geographers, [S.l.], v.32, n.1, jan., p.3-8. 2007.

PECK, Jamie. Remaking laissez-faire. Progress in Human Geography, Oxford, v. 32, n.1, fev. p.3-43, 2008.

Constructions of neoliberal reason. Nova York: Oxford University Press, 2010.

POLANYI, Karl. The economy as instituted process. In: Dalton, G. (Ed.) Primitive, archaic and modern economies. Boston: Beacon Press, [1957] 1971. p. 139-174

PRATT, John. Penal populism. Londres: Routledge, 2007.

RICHLAND, Justin B. On neoliberalism and other social diseases: the 2008 sociocultural anthropology year in review. American Anthropologist, [S.1.], v.111, n. 2, junho, p.170-176, 2009.

SAAD-FILHO, Alfredo; JOHNSTON Deborah (Ed.) Neoliberalism: a critical reader. Londres: Pluto, 2005.

SIMON, Jonathan. Governing through crime: how the war on crime transformed American democracy and created a culture of fear. Nova York: Oxford University Press, 2007.

TONRY, Michael H. Has the prison a future. In:

The future of imprisonment. Nova York: Oxford University Press. 2004. p.3-25

VOGEL, Steven K. Freer markets, more rules: regulatory reform in advanced countries. Ithaca, NY: Cornell University Press, 1996.

WACQUANT, Loïc. L'underclass urbaine dans l'imaginaire social et scientifique américain. In: PAUGAM, Serge (Ed.) L'exclusion: l'état des savoirs. Paris: La Découverte, 1996. p.248-262. [edição brasileira A 'underclass' urbana no imaginário social e científico norte-americano. Estudos Afro-Asiáticos, Rio de Janeiro, n. 31, p.37-50, out. 1997].

Three pernicious premises in the study of the american ghetto. International Journal of Urban and Regional Research, [S.l.], v.21, n.2,june, p.341-353, 1997; Events and Debate, [S.l.], p.341-353, 1997. [edicão brasileira, versão resumida, Três premissas perniciosas no estudo do gueto norte-ams resula te-americano. Mand Estudos de Antropologia Social, Rio de Janeiro, $v$ 2, n. 2, p.145-161, out. 1996].

Body and Soul: Notebooks of an Apprentice Boxer. Nova York: Oxford University Press, [2000] 2004. [edição brasileira Corpo e alma: notas etnográficas de um aprendiz de boxe. Trad. Ângela Ramalho. Rio de Janeiro: Relume Dumará, 2002].

(Ed.) Pierre Bourdieu and democratic politics: the mystery of ministry Cambridge, UK: Polity Press, 2005. [edição brasileira O mistério do ministério. Pierre Bourdieu e a política [edição brasileira $O$ mistério do ministério.

. Urban outcasts: a comparative sociology of advanced marginality. Cambridge, UK: Polity Press, 2008a.

Ordering insecurity: social polarization and the punitive upsurge. Radical Philosophy Review, Kingston, v.11, n.1, p. 9-27, primavera, 2008b.

Punishing the poor: the neoliberal government of social insecurity. Durham; London: Duke University Press, 2009a (Politics, culture, and history,series). [edição brasileira, versão resumida, Punir os pobres: a nova gestão da miséria nos Estados Unidos [A onda punitiva]. $3^{\mathrm{a}}$ ed. Trad. Sergio Lamarão. Rio de Janeiro: Ed. Revan, 2007].

Prisons of poverty. ed. rev. ampl.Minneapolis: University of Minnesota Press, 2009b. [edição brasileira As prisões da miséria. 10 ed. (com nova introdução e posfácio). Rio de Janeiro: Zahar , 2012].

The body, the ghetto and the penal state. 
Qualitative Sociology Review, Lodz, v.32, n.1, p.101-129, mar. 2009c. [edição brasileira O corpo, o gueto, e o Estado penal: no campo com Loïc Wacquant. Etnográfica, 12-3, p. 453-484, nov. 2008].

Crafting the neoliberal state: workfare, prisonfare and social insecurity. Sociological Forum, n. 25, n. 2, p. 197-220, junho, 2010a. [Publicados no Brasil: Apêndice teórico: um esboço do Estado penal. Discursos sediciosos, Rio de Janeiro, 17-18, p.137-162, primavera, 2010; A política punitiva da marginalidade: revisitando a fusão entre workfare e prisonfare. Trad. Julia Alexim. Revista Epos, Rio de Janeiro, UFRJ, v.13, n.1, jan./jun. 2012].

Forjando o estado neoliberal: trabalho social, regime prisional e insegurança social. Trad. Sergio Lamarão. In: BATISTA, Vera Malaguti (org.) Loïc Wacquant e a questão penal no capitalismo neoliberal. Rio de Janeiro: Revan, 2012.

. Prisoner Reentry as Myth and Ceremony. Dialectical Anthropology, v. 34, n. 4, p. 604-620, dez., 2010b. [edição brasileira. A reinserção do prisioneiro como mito e cerimônia. Trad. Sergio Lamarão. Discursos sediciosos, Rio de Janeiro, no prelo] .

The global firestorm of law and order: on neoliberalism and punishment. Thesis Eleven 105, outo- no, 2011. In: Seguido pelo comentário de Pat O Malley uma resposta, 2011. [edição brasileira A tempestade global da lei e ordem: sobre punicão e neoliberalismo. Trad. Sergio Lamarão. Revisto de Sociologia e Política, Curitiba, n. 41, p.7-20, fev. 2012].

WALMSLEY, Roy. World prison population list. 9.ed. Londres: International Center for Prison Studies, 2011.

WEBER, Max. Economy and society: an outline of interpretive sociology. Edited por Günther Roth e Claus Wittich. Berkeley: University of California Press, [19181920] 1978. 2 v.

WILLIAMSON, John H. Democracy and the Washington Consensus. World Development, [S.l.], v. 21, n. 8, p.1.3291.336, 1993

YOUNG, Warren; BROWN, Mark. Cross-national comparisons of imprisonment. Crime $\mathcal{E}$ Justice: a review of research, Chicago, v.17, p.1-49, 1993.

YOUNG, Jock. The exclusive society: social exclusion, crime and difference in late modernity. Londres: Sage, 1999. 


\section{THREE STEPS TO A HISTORICAL ANTHROPOLOGY OF ACTUALLY EXISTING NEOLIBERALISM}

\section{Loïc Wacquant}

The anthropology of neoliberalism has become polarized between a hegemonic economic model anchored by variants of market rule and an insurgent approach fueled by derivations of the Foucaultian notion of governmentality. Both conceptions obscure what is "neo" about neoliberalism: the reengineering and redeployment of the state as the agency that sets the rules and fabricates the subjectivities, social relations, and collective representations suited to realizing markets. I develop Bourdieu's concept of "bureaucratic field" to propose a via media between these two approaches that construes neoliberalism as an articulation of state, market, and citizenship that harnesses the first to impose the stamp of the second onto the third. This conception repatriates penality at the core of the production of a Centaurstate that practices laissez-faire at the top of the class structure and punitive paternalism at the bottom.

Keywords: Neoliberalism. Governmentality. Bureaucratic field. Penal state. Workfare. Bourdieu

\section{TROIS PROPOSITIONS POUR UNE ANTHROPOLOGIE HISTORIQUE DU NÉOLIBÉRALISME RÉEL}

\author{
Loïc Wacquant
}

L'anthropologie du néolibéralisme est polarisée entre un modèle économique hégémonique, ancré par la notion d'empire du marché, et une approche rebelle, nourrie par des dérivations de la notion foucaultienne de gouvernementalité. Ces deux conceptions antagonistes convergent en ceci qu'elles dissimulent ce qui est "néo" dans le néolibéralisme: le recalibrage et le redéploiement de l'État comme instance qui fixe des règles et fabrique les subjectivités, les rapports sociaux et les représentations collectives propices à la réalisation des marchés. Je développe le concept de "champ bureaucratique" chez Bourdieu pour frayer une voie moyenne entre ces deux approches qui conçoit le néolibéralisme comme une articulation entre Etat, marché et citoyenneté qui mobilise le premier terme pour imprimer le second sur le troisième. Cette conception rapatrie la pénalité au coeur de la production d'un État-centaure qui pratique le laissez-faire en haut de la structure de classe et le paternalisme punitif en bas.

Mots-CLEFS: Néoliberalisme. Gouvernementalité. Champ bureaucratique. État pénal. Politique sociale disciplinaire. Bourdieu

Loïc Wacquant - Professor de Sociologia na Universidade da Califórnia, Berkeley, e pesquisador no Centro de Sociologia Europeia, Paris. Publicou numerosos trabalhos comparativos sobre marginalidade urbana, corporificação, Estado penal, dominação etnorracial e teoria social, traduzidos em mais de 20 de línguas. Seus livros no Brasil incluem: Corpo e alma. Notas etnográficas de um aprendiz de boxe (2002), O mistério do ministério. Pierre Bourdieu e a política democrática (2005), Onda punitiva. O novo governo da insegurança social (2007) e As duas faces do gueto (2007). 